\title{
KARAKTERISTIK AMPLIFIER CLASS D MENGGUNAKAN FIELD EFFECT TRANSISTOR (FET) TYPE IRF9530 DAN IRF630
}

\author{
Budi Santoso ${ }^{1}$, Zainal Abidin² \\ ${ }^{1,2}$ Program Studi Teknik Elektro, Fakultas Teknik, Universitas Islam Lamongan \\ Jl. Veteran No. 53A Lamongan Telp. 0322 - 324706, Fax. 0322 - 317116 \\ Email: ${ }^{1}$ budisantos99392@gmail.com, ${ }^{2}$ zainalabidin@unisla.ac.id
}

\begin{abstract}
In the development of power amplifiers, MOSFETs are widely used in the composition of the manufacture. As is known, MOSFETs have a longer on-off time loss compared to IGBT. The loss on the on-off time has an impact on the heat generated by the MOSFET. Class D Audio Amplifier is basically a Switching-Amplifier or Pulse Width Modulation-Amplifier. High efficiency means that it will produce low power dissipation, thus the power wasted is relatively lower when compared to class $A, B$ or $A B$ amplifiers. Because the class D audio amplifier can be said to be more economical because it does not require a large heatsink and a large power supply. The manufacture of the Class D power amplifier system uses a voltage of 28.5 volts DC on the final transistor IRF9530 AND IRF630 measuring the input transistors of 3.3 volts DC, 28.5 volts DC. In the test using an oscilloscope type LS 8050, $50 \mathrm{MHz}$ frequency, the position of the audio input off of the amplifier has sound defects. Testing of the power amplifier is carried out when the treble on the input tone control is full db in the defective amplifier wave.
\end{abstract}

Keywords: Power Amplifier, Class D Audio Amplifier, Field Effect Transistor

\section{PENDAHULUAN}

Penguat audio kelas D adalah penguat audio yang bekerja dengan prinsip binary-switches. Sejak digunakannya power MOSFET, maka menjadikan binary-switches lebih sempurna, sehingga tidak ada waktu transisi terbuang dan tidak ada daya terbuang saat masukan penguat ini nol. Penguat audio kelas D memiliki efisiensi yang jauh lebih baik dibandingkan penguat-penguat audio pendahulunya seperti penguat kelas A, kelas B dan kelas AB. Penguat audio kelas $\mathrm{AB}$ secara teoritis mempunyai efisiensi paling bagus sekitar 78,5\% sebelum dibebani speaker. Saat dibebani speaker efisiensinya bisa turun menjadi $50 \%$. Saat ini penguat audio kelas D mempunyai efisiensi 90\% saat dibebani speaker. Sementara secara teoritis penguat audio Kelas D mempunyai efisiensi ideal $100 \%$.Efisiensi yang tinggi berarti akan menghasilkan disipasi daya yang rendah, dengan demikian daya yang terbuang relatif lebih rendah jika dibandingkan penguat kelas A, B maupun AB. Karena penguat audio kelas D bisa dibilang hemat daya maka penguat ini tidak membutuhkan pendingin (heatsink) yang besar dan catu daya yang besar pula.

Rumusan masalah dari penelitian adalah : (a) Bagaimana Merancang Amplifier Class D Menggunakan Field Effect Transistor(FET) type IRF9530 DAN IRF630?, (b) Bagaimana kinerja Amplifier Class D Menggunakan Field Effect Transistor (FET) type IRF9530 DAN IRF630?

\section{METODE}

\subsection{Power Amplifier Class D}

Penguat kelas (Power Amplifier) Class D menggunakan teknik PWM (pulse width modulation), dimana lebar dari pulsa ini proporsioal terhadap amplituda sinyal input. Pada tingkat akhir, sinyal PWM men-drive transistor switching ON dan OFF sesuai dengan lebar pulsanya.Transistor switching yang digunakan biasanya adalah transistor jenis FET.Konsep penguat kelas D ditunjukkan pada gambar-11. Teknik sampling pada sistem penguat kelas D memerlukan sebuah generator gelombang segitiga dan komparator untuk menghasilkan sinyal PWM yang proporsional terhadap amplituda sinyal input. Pola sinyal PWM hasil dari teknik sampling ini seperti digambarkan pada gambar-12.Paling akhir diperlukan filter untuk meningkatkan fidelitas.

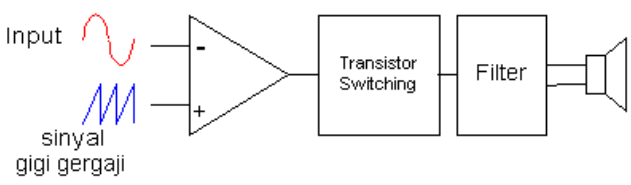

Gambar 1. Konsep penguat kelas D 


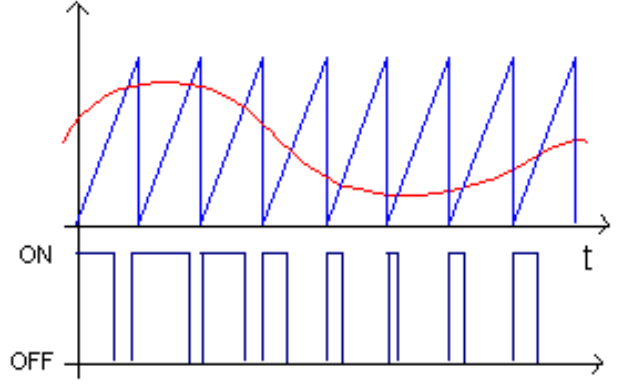

Gambar 2. Ilustrasi modulasi PWM penguat kelas D

Beberapa produsen pembuat PA meng-klaim penguat kelas D produksinya sebagai penguat digital.Secara kebetulan notasi D dapat diartikan menjadi Digital. Sebenarnya bukanlah persis demikian, sebab proses digital mestinya mengandung proses manipulasi sederetan bit-bit yang pada akhirnya ada proses konversi digital ke analog (DAC) atau ke PWM. Kalaupun mau disebut digital, penguat kelas D adalah penguat digital 1 bit (on atau off saja).

\subsection{BahanPenelitian}

\section{Power Supply}

Fungsi alat ini sebagai penyupplay tegangan.Tegangan yang di keluarkan dari power supply adalah27v ini yang di butuhkan oleh rangakaian power amplifier Class D.

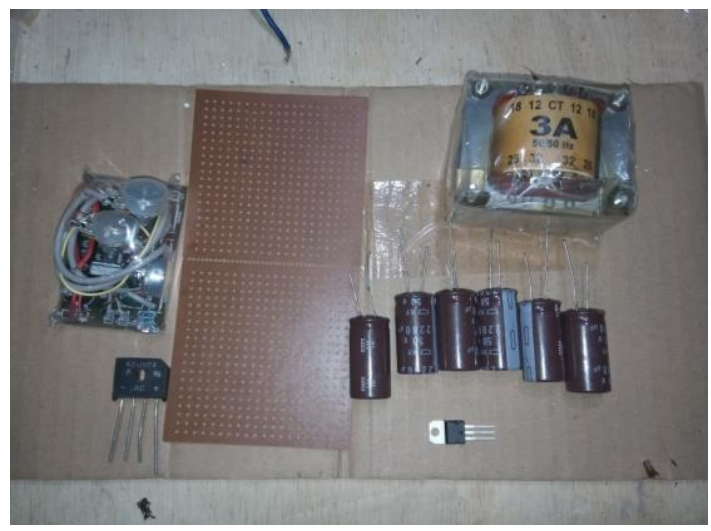

\section{Gambar 3.Komponen Power Supply}

\section{IC OP-AMP}

IC Op-amp TL074 Berfunsi sebagai penguat dan perata pada sistem pedukung power amplifaier Class D.

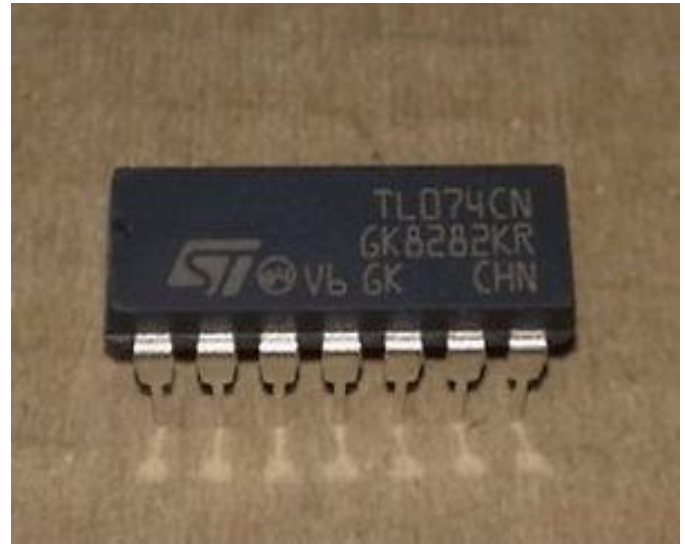

\section{Gambar 4. IC OP-AMP TL074}

\section{Resistor}

Resistor berfungsi sebagai pengkople arus pada rangkaian power amplifier class $d$, secara otomatis dan sebagai penurun teganganUkuran resistor yang digunakan:

Resistor 22k 4 biji., 2.2K, 1K, 680 ohm, 100K, 220 ohm, 470 ohm, 22K, 56K, 47K, 33K, 1M.,47k, 220ohm, 560ohm, 2k2, 10k, 15k,

\section{Capasitor}

Kapasitor ini digunakan sebagai filter pada rangkaian power amplifier class $d$ Kapasitor yang dipasang berfungsi sebagai filter dan menapung tegangan yang di konsumsi oleh power amplifier class d.Capasitor 104n/450n.Capasitor 100n/100v.Capasitor elektrolite $3300 \mu \mathrm{f} / 50 \mathrm{v} \quad 8$ buah.Capasitor 1Uf, 100uf, 100nF, 1000uf. 820pf. Kapasitor elco, 100uf/25v, 10uf/16v, 47nf, $100 \mathrm{nCapasitor} 100 \mathrm{n} / 250 \mathrm{v}$.

\section{Transistor}

Transistor ini berfungsi sebagai pembangkit ferkuensi dan sinyal osilator dan transistor final, komponen dalam pembuatan amplifier ini adalah IRF9530 dan IRF530.

\section{HASIL DAN PEMBAHASAN \\ a. Pengujian alat \\ 1) Pengujian power supply}

Pengujian menggunakan avometer untuk mengetahui tegangan yang masuk pada amplifier dengan catudaya 27,9 volt 


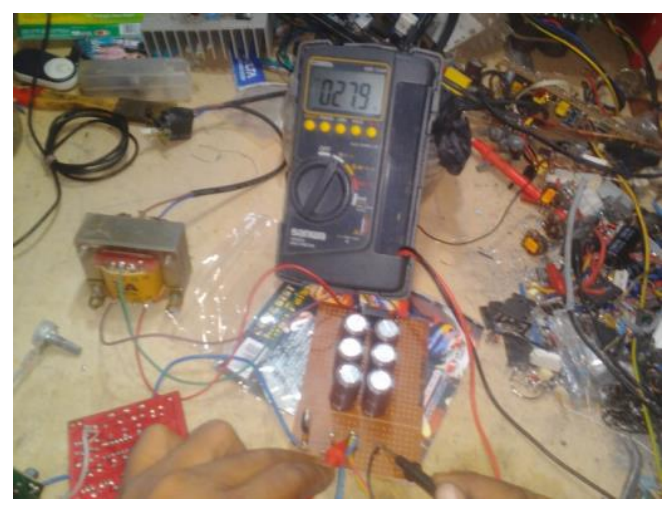

Gambar 5. Pengujianpada power supply

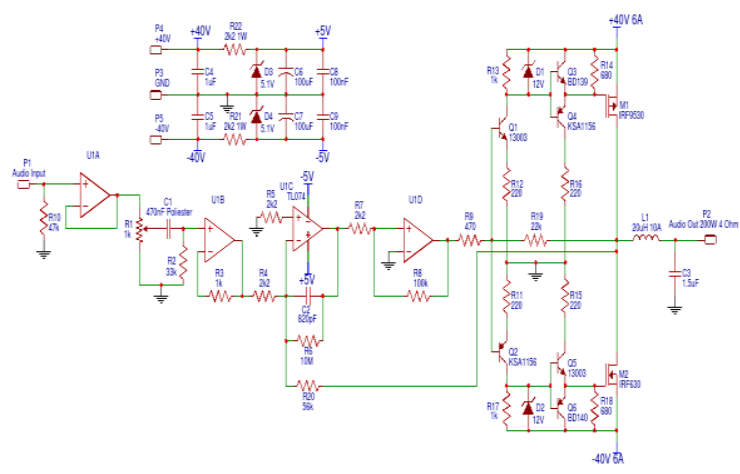

\section{2) Pengujian amplifier Class D}

Pada penelitian amplifier class d ini pengujian pada kaki transistor IRF530 DAN IRF9530. Apakah supply daya masuk padarangkian amplifier dan untuk mengetahui adanya cacat tegangan yang masuk.

\section{3) Pengujian tone kontrol}

Pada pengujian tone control ini sangat berpengaruh pada penelitian yang dilakukan, makadar iitu pengujian pada tone control ini mengetahui apa ada noise pada rangkian tone control.

\section{4) Pengujian alat keseluruan}

Pada pengujian alat keseluruan dimana pengujian dilakuakan untuk mengetahui pengaruh efesiensi amplifier class d pada nada tinggi (high tone )menggunkan tone control saat volume high diputar full, dengan pembanding saat volume low diputar full. Pengujian juga dilakukan menggunakan osiloskop untuk mengetahui frequensi saat tone control volume high diputar full dan saat tone control volume low diputar full.Pengamatan juga dilakukan pada heatsink pada amplifier class D.
Tabel 1 Pengujian Hasil Pengujian Rangkaian Power Supply menggunakan avometer.

\begin{tabular}{|c|c|c|c|}
\hline No & Objek Yang Diukur & $\begin{array}{c}\text { Pengukuran } \\
\text { input (Volt) }\end{array}$ & $\begin{array}{c}\text { Pengukuran } \\
\text { output(Volt) }\end{array}$ \\
\hline 1 & Transformer & 212 Volt AC & 28,5 Volt DC \\
\hline 2 & $\begin{array}{c}\text { Power supply positive and } \\
\text { ground }\end{array}$ & - & 27,9 Volt DC \\
\hline 3 & $\begin{array}{c}\text { Power supplynegativ and } \\
\text { ground }\end{array}$ & - & 27,9 Volt DC \\
\hline 4 & $\begin{array}{c}\text { Power supply } \\
\text { teganganpada tone kontrol }\end{array}$ & - & 11,8 Volt DC \\
\hline
\end{tabular}

. Tabel 2 Pengujian Hasil Pengujian Rangkaian power amplifier class $D$ menggunakan avometer.

\begin{tabular}{|c|c|c|}
\hline NO & $\begin{array}{l}\text { Qbyek Yang DiukurPada } \\
\text { Amplifier }\end{array}$ & $\begin{array}{c}\text { Pengukuran Input Tegangan } \\
\text { (Volt) DC }\end{array}$ \\
\hline 1 & 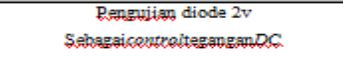 & 05,1 Volt DC \\
\hline 2 & Pengujian Diode zenex $12 v$ ngeatix & 4,8 Volt DC \\
\hline 3 & Pengujian Diode zencx $12 v$ p $Q$ sitivi & 5,3 Volt DC \\
\hline 4 & $\begin{array}{c}\text { Pengujian transistor } 2 n 5551 \mathrm{~kg} \\
\text { ground }\end{array}$ & 23,5 Volt DC \\
\hline 5 & $\begin{array}{c}\text { Pengujian transistor } 2 n 5401 \mathrm{ke} \\
\text { ground }\end{array}$ & 23,4 Volt DC \\
\hline 6 & $\begin{array}{c}\text { PengujianTransistorBD139 basiske } \\
\text { Ground }\end{array}$ & 28,8 Volt DC \\
\hline 7 & $\begin{array}{c}\text { Pengujian Transistor BD140 basiske } \\
\text { Ground }\end{array}$ & 28,5 Volt DC \\
\hline 8 & $\begin{array}{c}\text { Pengujian Transistor IRF540 ke } \\
\text { Ground }\end{array}$ & 20,5 Volt DC \\
\hline 9 & $\begin{array}{c}\text { Pengujian Transistor IRF540 ke } \\
\text { Ground }\end{array}$ & 28,9 Volt DC \\
\hline 10 & $\begin{array}{c}\text { Pengujian Transistor IRF9540 ke } \\
\text { Ground }\end{array}$ & 3,3 Volt DC \\
\hline 11 & $\begin{array}{c}\text { Pengujian Transistor IRF9540 ke } \\
\text { Ground }\end{array}$ & 28,5 Volt DC \\
\hline
\end{tabular}

\section{KESIMPULAN}

Pembuatan sistem power amplifier Class D menggunakan tegangan 28,5 $+D C$ pada transistor final IRF9540 DAN IRF540 pengukuran volt input transisor 3,3 Volt DC, 28,5 Volt DC.

Pada pengujian menggunakan osiloskop type LS 8050 frekuensi $50 \mathrm{MHz}$ posisi input audio off amplifier cacat suara.

Pengujian terhadap power amplifier dilakukan saat treble pada tone control yang diinputkan dalam kondisi full db pada gelombang amplifier cacat. Penggunaan transistor yang berbeda ukuran berpengaruh pada kuwalitas suara.

Disarankan Penggunaan Power Supply Menggunakan travo Switcing. Untuk dapat membuat power amplifier class dyang lebih baikdigunakan untuk asumsi speaker yang berdaya besar. Tidak anjurkan untuk Penggunaan pada sound sistem besar. 


\section{PUSTAKA}

Beni Juniarto Rahmad Raharjo, skripsi dengan judul Pengembangan Trainer Audio Amplifier Class D Dan Class H Sebagai Media Pembelajaran Kelas Xii Program Keahlian Teknik Audio Video Di Smk Muhammadiyah 3 Yogyakarta, 2016.

Elektronika Dasar. http://elektronikadasar.web.id/artikel-elektronika/driver-motor-dch-bridge-transistor/. Di akses tanggal 03 Juni 2014

Ferri Julianto, Tugas Akhir Yang Berjudul Perancangan Muti Band Power Amplifier ClassE Padafrekuensi 900 Mhz, 1800 Mhz, 2300 Mhz, Dan 2600 Mhz. .2012

Gaalaas Eric. (2006). Class D Audio Amplifiers : What, Why, and How. Analog Dialogue 40 - 06. Hlm 1-7.

Honda Jun \& Adams Jonathan. (2005). Class D Audio Amplifier Basics. International Rectifier. California. Maldonado Joseph \& Vega Jeovany. (2010). Class D Power Amplifier. California Polytechnic State University. San Luis Obispo.Susanto. 2012.

Ivan Christanto, Mono Amplifier Class D menggunakan Semikron SKHI 22B dan IGBT Module Semikron SKM75GB128DN Jurnal Dimensi Teknik Elektro Vol. 1, No. 1, (2013) 29-36

M. Noor Effendi Dan K. Amien Sunarto. Desain \& kontruksi amplifaier, januari 2009.

Nuryadi, skripsi , optimasi differensial operasional amplifier CMFB dengan VDD1 VOLT DAN SLEW RATE $1500 \mathrm{Mv} / \mathrm{Ns} .2010$

Syahrianto wibowo. Pintar \& trampil elektronika merakit dan meraparasi sendiri, penerbit terbit terang, surabaya.

Suryo Santoso, F. Dalu Setiaji, Matias H.W. Budhianto, Penguat Audio Kelas Tanpa Tapis Lc Dengan Modulasi Tiga Aras Techné Jurnal Ilmiah Elektroteknika Vol. 12 No. 1 April 2013 Hal $61-74$.

Tim Skripsi, 2014 Pedoman Penulisan Skripsi. Fakultas Teknik Universitas Islam Lamongan

Sumber: $\quad$ Http://Teknikelektronika.Com/KelebihanKeterbatasan-Ic-Integrated-Circuit/ 